\title{
El racismo como ideología y su negación en nuestras sociedades
}

The racism as an ideology and its denial in our societies Hilda Beatriz Quintero Corrales ${ }^{1}$ y Alexander Murillo Moreno 2

\section{Resumen}

Fuera de todo concepto, explicar el fenómeno del racismo hacia comunidades afrodescendientes e indígenas, centrado en la segregación es una empresa compleja; hablar de racismo es expresarlo en relación al color y la etnia, sin aislar la existencia del ser humano; ello conlleva a un sinnúmero de elementos que configuran la discriminación hacia estos grupos sociales justificada por una cuestión de creencias e ideologías arraigadas, las cuales garantizan un sistema de opresión, desigualdad y subyugación. En Colombia, ideas racistas son promovidas desde narrativas públicas lideradas por referentes y políticos de la élite nacional cuyos juicios dan mayor sustento a la segregación. Los estereotipos han modificado costumbres y creencias de los segregados alterando su idiosincrasia; algunos cansados del asedio eligen parejas blancas para que sus descendientes tengan piel más clara, alejándolos de la segregación y facilitando el acceso a mayores oportunidades, aunque en el proceso tienden a perder su identidad. El racismo es una práctica disimulada, sutil e hipócrita. Los derechos de las minorías y su protección están en el imaginario, pues el Estado no está en condiciones, ni tiene la voluntad para hacer efectivo su reconocimiento legal; la lucha para defenderlos debe darse de forma más abierta, traspasando fronteras geopolíticas.

Palabras clave: Racismo, segregación, ideología, identidad, estereotipos

\section{Abstract}

Beyond all concepts, explaining the phenomenon of racism towards afro-descendant and indigenous communities, centered on segregation is a complex undertaking; to speak of racism is to express it in relation to color and ethnicity, without isolating the existence of the human being; this leads to countless elements that make up the discrimination towards these social groups justified by a matter of deeply rooted beliefs and ideologies, which guarantee a system of oppression, inequality and

Recibido: 31 de marzo de 2021 Aceptado: 30 de junio de $2021 \sim$ Publicado: 8 de julio de 2021

1 Tecnóloga en regencia de farmacia. Universidad Nacional Abierta y a Distancia (UNAD), Medellín, Colombia. Correo electrónico hildaquin@hotmail.com ID https://orcid.org/0000-0002-3501-9719

2 Magister en Educación. Universidad de Antioquia (UdeA), Medellín, Colombia. Correo electrónico alexanderm54@gmail.com ID https://orcid.org/0000-0002-3760-5383 
subjugation. In Colombia, racist ideas are promoted from public narratives led by referents and politicians of the national elite whose judgments give greater support to segregation. Stereotypes have modified customs and beliefs of the segregated, altering their idiosyncrasy; some weary of the siege choose white couples so that their descendants have lighter skin, distancing them from segregation and facilitating access to greater opportunities, although in the process they tend to lose their identity. Racism is a sneaky, subtle, and hypocritical practice. The rights of minorities and their protection are in the imaginary, since the State is not in a position, nor does it have the will to make their legal recognition effective; the fight to defend them must take place in a more open way, crossing geopolitical borders.

Keywords: Racism, segregation, ideology, identity, stereotypes

\section{Introducción}

Explicar el fenómeno del racismo y comprender cómo deriva en comportamientos de segregación hacia las comunidades afro-descendientes e indígenas es una empresa que se torna un tanto compleja, pues hablar de racismo es expresar conceptos relacionados con la raza, el color o la etnia sin aislar la existencia del ser humano subyacente; ello sin duda conlleva a un sinnúmero de elementos que dan forma a una marcada desigualdad entre personas cuya naturaleza fisiológica es igual.

La desigualdad implícita en el racismo engloba una forma de discurso cuya conducta discriminatoria se enmarca en prejuicios y prácticas de clasificación, que generalmente están ancladas en creencias e ideologías para designar la inferioridad basada en la raza, conformando así un sistema de opresión que con frecuencia se materializa en actos de segregación (social, económica y política), aún en contra de una inobjetable alteridad que reconoce la condición de ser otro, de ser diferentes.

En el contexto del racismo se pasa por alto la condición de alteridad, pues se propician relaciones de inequidad sin tener en cuenta esa condición de ser otro o de ser distinto desde la perspectiva del yo individual, respecto de lo cual Hopenhayn y Bello (2001) exponen que "La negación del otro presenta, en su desarrollo histórico, matices diversos ..., la negación parte de un doble movimiento: de una parte se diferencia al otro respecto de sí mismo, y en seguida se lo desvaloriza y se lo sitúa jerárquicamente..." (p.9), configurando así una concepción del mundo desde la óptica de un otro cuyos intereses están determinados por sus costumbres, tradiciones e ideales, y aunque son diferentes, forman parte de un todo social lo cual implica ponerse en el lugar de ese otro, teniendo en vista la perspectiva propia con la suya, 
toda vez que esa diferencia debe reflejar una muestra de interés por comprenderle, concibiéndose como punto de partida en la interacción entre diversos grupos sociales.

El racismo en la concepción de nuestras sociedades olvida la composición genética del cuerpo humano (formado por 23 pares de cromosomas, y cantidad de huesos iguales) más allá de la herencia biológica y sin importar el color de la piel, vida que concluye con la muerte en un proceso que sin excepción expone al cuerpo a un inevitable estado de descomposición; tal realidad invita a reflexionar entendiendo y aceptando las diferencias para transcender la identidad y reconocer la alteridad del otro como una relación a través de la disensión, enmarcada en una visión compartida hacia un objetivo común: reemplazar el ideal de la segregación por una verdad universal desde las particularidades en un mundo cada vez más diverso y cambiante, en el cual prevalece la discriminación caracterizada por un trato desigual y lesivo hacia las minorías, vulnerando sus derechos.

Tal como lo expone Wade (2010) particularmente en el contexto de Colombia y Brasil "los temas de racismo ... han vuelto a ser el centro del escenario, orientando el debate étnico hacia la lucha contra la discriminación y el racismo...donde la preocupación por la desigualdad racial tiene una larga historia,...” (p.123), tema que no siempre ha sido suficientemente sensible con todos los grupos sociales afectados, y que es especialmente digno de atención pues sus acciones se transfieren en violencia personal, comunitaria, e institucional, con una alta carga psicológica asociada con los extremos del absolutismo estatal y el relativismo de la clasificación racial validando tal problemática, además de las prácticas totalizadoras en virtud de tendencias fragmentarias que desvían la atención de un potencial debate del problema.

En línea con aspectos asociados a la clasificación racial se da la interacción tanto física como cultural entre las poblaciones que coexisten en los territorios de América Latina y Estados Unidos, surgiendo en el proceso una serie de cruces raciales entre las etnias que convivían; mezclas raciales, producto de la relación principalmente entre blancos y negras o negros e indias, con lo cual se origina el mestizaje.

Al respecto indica Wade (2003) que “... el mestizaje se mira como un proceso más o menos disfrazado de blanqueamiento,..." (p.277), que en ningún caso permite eliminar los prejuicios raciales; acota además Wade (2021) respecto al mestizaje que “... es un rasgo persistente de las formaciones raciales latinoamericanas, ... el término refiere a los procesos de interacción sexual entre europeos, africanos e indígenas de América que comenzaron en el siglo XVI y que dieron lugar a poblaciones de mestizos, ..." (p. 25), lo cual dio lugar a la jerarquización de las variantes de la segregación y el racismo ya que para Mosquera y León (2010) "el proceso de mestizaje se configuró como práctica encaminada al progreso, ... visto como un proceso 
evolutivo de blanqueamiento. Este proceso de mestizaje representaba para los criollos un éxito cuando se daba la mezcla del blanco con un color inferior... (p.14).

Vemos entonces que en medio de ese proceso de "blanqueamiento" se modifica gradualmente a las poblaciones en un intento de homogeneizar la diversidad étnica y cultural que las caracteriza, al tiempo que aquellos afectados por la desigualdad racial y la discriminación intentan integrarse a la sociedad exitosamente, aunque tal como lo plantea Wade (2021) “...En Brasil y en América Latina más en general, el mestizaje modeló la formación racial de manera importante: el racismo opera a través de él, pero de un modo que dificulta reconocerlo como tal." (p. 34), lo cual corrobora el ocultamiento de una realidad de exclusión racista detrás de una máscara de inclusión en medio del mestizaje.

Al final, la justificación de la discriminación impuesta a ciertos grupos sociales pasa bien sea por una cuestión de creencias o de una ideología arraigada, fundamentada en la inferioridad racial para garantizar un sistema de opresión donde impera la ley del más fuerte, garantizada por un grupo que posee los recursos necesarios para ejercer dominación y subyugación.

\section{El racismo como una creencia o una ideología de la inferioridad racial}

Más allá de toda persuasión, es notable en América Latina (en el marco del desarrollo de la colonización, siglos XV al XIX) y en EE. UU. (con el surgimiento del esclavismo, siglos XVII al XIX) la imposición de que los hombres blancos eran superiores. Frente a ello, por un lado Wade (2010) plantea que "en los EE. UU.... los blancos pobres que eran mayoría, aseguraron que la categoría 'negro' fuera fuertemente asociada con el racismo y las restricciones legales, e intentaron convertir a todos los negros en esclavos implantando las categorías raciales.” (p.52), y por el otro, Carbone (2013) expresa que "claramente el concepto de raza representa una racionalización de un sistema de opresión, explotación y dominación, elaborado en un contexto histórico particular, fuertemente enraizado en las estructuras de poder de la clase dominante blanca." (p.9), lo cual se complementa con lo indicado por Grunstein (2005) cuando expone que “... para justificar la explotación de los esclavos, la elite plantadora elaboró y promovió una serie de nociones acerca de la superioridad anglo-sajona y la inferioridad africana innata ... preceptos en los que se basó posteriormente la instauración del sistema de segregación” (p.96), y pese a haber transcurrido muchos años, las condiciones de inequidad racial originadas en el contexto de la esclavización ${ }^{3}$ están activas en América Latina y EE.UU, manifestadas

\footnotetext{
${ }^{3}$ En el caso de América, Cartagena - Colombia se considera como el primer destino para un navío esclavista en el año 1549, marcando el inicio del traslado de africanos a estas tierras y sometidos a trabajar de manera
} 
en la situación de discriminación estructural que en particular experimentan los afrodescendientes, en razón de que "el Estado... no ha reconocido la existencia del racismo y la discriminación racial..., ha protegido el legado histórico del racismo estructural, institucional, social, y cultural heredado de la colonia y de la república...” (Mosquera y León, 2010, p.51)

La idea de la superioridad de los blancos representada en la discriminación es afianzada desde la culturización forzada por la iglesia a los grupos de esclavos, lo cual decantó en la subyugación y en las prácticas sociales de clasificación racial donde "la elite englobó a indios, mulatos y negros en una única clase paria, y en la clase dominante a grandes y pequeños plantadores blancos ... Fue a través del sistema legal que el racismo se racionalizó e institucionalizó como ideología” (Carbone, 2013, p.5), generando el sometimiento de grupos sociales a quienes se les negó su condición humana desde una creencia anclada en la supuesta inferioridad racial institucionalizando todo un sistema de opresión social basado en la raza, una forma de discurso a partir de una conducta discriminatoria caracterizada por una actitud de desdén.

En el marco de la proclamación de ideologías supremacistas como en Virginia, EE. UU, "Una ley de 1682 convirtió en esclavos a todos los sirvientes no cristianos importados. Dado que sólo los indios y africanos encajaban en esta descripción, esta ley dio lugar al desarrollo de la esclavitud sobre un fundamento racial.” (Ibid., p.6), principio que derivó en todo un sistema de rígidas prácticas discriminatorias caracterizadas por hostilidad y desprecio, acompañadas del maltrato en todas sus facetas (físico, verbal, sicológico y social), implantando un sinnúmero de tradiciones segregacionistas cuyo propósito primordial era oprimir a los descendientes de los africanos, lo cual representa destacados conceptos de ideología que se asumen aquí como representaciones simbólicas globalizantes que definen prácticas raciales e integran a los grupos segregados bajo cualidades y juicios predefinidos, conceptos entre los cuales podemos destacar el caso de la ley Jim Crow que de acuerdo con Pérez (2010) "era un código de segregación racial... que tenía, además, el objetivo de dar señales públicas y evidentes de la supremacía blanca." (p.122), estableciendo un sistema de privaciones en contra de los negros y sus descendientes que afectaría su vida en todos los ámbitos, al estructurar numerosas desventajas económicas, educativas y sociales.

Las leyes Jim Crow derivadas de los códigos negros (1800-1866), fueron leyes estatales y locales en EE. UU. promulgadas por las legislaturas blancas después del período de reconstrucción (1865-1877), las cuales respaldaban la segregación racial

forzosa en diferentes actividades económicas, durante los siglos de existencia de la esclavización, hasta 1851 cuando fue formalmente abolida. (Romaña, 2020, p.19) 
abarcando todas las instalaciones públicas bajo el lema «separados pero iguales», y se aplicaban a los afro-estadounidenses y a otros grupos étnicos no blancos, limitando los derechos y las libertades civiles. "Lo que hizo el Jim Crow fue rebajar aún más el estatus del negro" (Pérez, 2010, p.122), puesto que tal como lo plantea Carbone (2013) "pasó a ser sinónimo de ciudadanía de segunda clase, separación racial, servicios públicos "separados y desiguales" o inexistentes para los negros; privación de derechos políticos y electorales, empleos de baja remuneración, ausencia de movilidad social.” (p.17), sometimiento que, pese a estar oculto a la vista de todos ha ido mutando, volviéndose más cuidadoso, actuando con cautela en el entorno social, a lo cual se acota la observación de París (2002) cuando plantea que “...la ideología racista parece difuminarse en todas las instituciones sociales modernas: la vivienda, la escuela, la empresa, el sindicato, la policía, etcétera” (p.293), instituciones de acceso público y general cuya facilidad de infiltración permite esconder acciones intencionadas, sin que ello pueda notarse justo en medio de la discusión de la esencia del racismo.

Al revisar los acontecimientos que dieron comienzo a que se instituya el racismo como una ideología de la inferioridad racial, un paso obligado es comprender que, la esclavitud de los negros en Carolina del Sur y otras colonias sureñas, consolidada en las primeras décadas del siglo XX y que permaneció vigente hasta mediados de siglo, se fue institucionalizando pese a su abolición gradual después del período de reconstrucción (1865-1877), con acuerdos llenos de ambigüedades que solo reemplazaron la esclavitud con la servidumbre, con todo tipo de prohibiciones, tratándolos como propiedad y no como personas. Este período de reconstrucción dio origen a un punto de inflexión para la ideología racial ya que se reajusta la esclavitud como sistema de producción económica y organización socio-política, sin que los esclavos y sus descendientes (población afroamericana) ocuparan un lugar en dicha sociedad pese a la libertad adquirida (Carbone, 2013), lo que explica el poder del racismo y la contextualización económico-política de los individuos racistas, sus grupos raciales y la extensión de sus consideraciones a todo tipo de actividad social en que blancos y negros pudieran entrar en contacto.

La reiterada negación de derechos conllevó a una extensa lucha; ello fue el precio exigido para legitimarla y que se impusiera la nueva renovación cultural de los afroamericanos, y que en cierto modo se dimensiona con la decisión de la Corte Suprema de los EE. UU. en el caso Brown ${ }^{4}$ contra el Consejo de Educación de Topeka en 1954, cuyo resultado fue una sentencia judicial que declaró que las leyes estatales que establecían escuelas separadas para estudiantes afroamericanos y blancos negaban

\footnotetext{
${ }^{4}$ Thurgood Marshall fue reconocido como abogado tras su victoria en el caso Brown, y quien a la postre sería el primer afroamericano elegido juez de la Corte Suprema de los EE. UU.
} 
la igualdad de oportunidades, decisión cuya relevancia radica en que puso en tela de juicio todo el sistema Jim Crow y sacudió los fundamentos ideológicos que lo sustentaban, estableciendo bases más sólidas para desestructurarlo; en general, el resto de las leyes Jim Crow se anularon por la Ley de Derechos Civiles de 1964 y la Ley de derecho al voto de 1965, dando plena apertura a la legitimación de la lucha de la población afrodescendiente por los derechos civiles, desconocidos hasta entonces (Carbone, 2013; Maestro, 2009).

En línea con los logros adquiridos en materia de derechos civiles por parte de los afroamericanos, en Colombia las comunidades negras expuestas al racismo histórico y actual aprecian el reconocimiento de derechos colectivos en función de su estatus como grupo étnico portador de una identidad propia y no del color de la piel de sus integrantes, lo cual está plasmado en la Sentencia C-169 de 20015 , y se complementa con el planteamiento de Wade (2011) de que “... la Ley 70 de 1993... otorgó derechos y protecciones a las 'comunidades negras' del país, ... reconociéndolas como 'grupo étnico' con ciertas características culturales..., sugiere un criterio de identificación evitando una referencia directa a la raza como criterio de identificación social..., (p.22), criterio que tal vez se emplea para no caer en posibles contradicciones, toda vez que “... la Ley 70, que se dirige a las comunidades negras del país, habla muy poco del racismo y mucho menos admite el concepto de raza como una manera de entender la especificidad de los afrocolombianos" (Ibid., p.22).

Frente a la apertura de derechos civiles de los afroamericanos con el final del sistema Jim Crow (entre 1964 y 1965), se sacuden los fundamentos ideológicos que sustentaban el racismo, aunque no implicó el fin de la opresión ejercida por la supremacía de los blancos; sin embargo, en esa apertura a la lucha por los derechos civiles se genera una confluencia cultural de la diversidad africana sin precedentes dando paso a la proliferación de multiplicidad de géneros culturales, poniendo en tela de juicio que el racismo sea una ideología causada por la inferioridad racial, ya que de la mano de cierta libertad, y conforme pasaba el tiempo, se observa de manera curiosa que la supuesta inferioridad estaba solo en el imaginario de la clase dominante, toda

\footnotetext{
5 Sentencia C-169 de 2001: el término "comunidades negras", como lo indica el artículo 1 de la Ley 70 de 1.993 en consonancia con el artículo Transitorio 55 de la Constitución, se refiere tanto a aquellas que habitan en la Cuenca del Pacífico colombiano, como a las que estén ubicadas en otros puntos del territorio nacional y cumplan con los dos elementos reseñados. Asimismo, a falta de una mención expresa, se deben entender incluidas dentro de las dichas "comunidades negras", para todo lo relacionado con la circunscripción especial que se estudia, a las agrupaciones raizales del Archipiélago de San Andrés y Providencia, las cuales no sólo comparten con las primeras un origen histórico común en las raíces africanas que fueron trasplantadas a América, sino que han sido reconocidas en consonancia con el artículo 310 de la Carta, como un grupo étnico titular de derechos especiales (Sentencias C-530/93, T-174/98 y C-1022/99); por lo mismo, no pueden ser razonablemente excluidas de la participación en la Cámara de Representantes por esta circunscripción. Consultado en https://www.corteconstitucional.gov.co/relatoria/2001/C-169-01.htm
} 
vez que representantes de la clase dominada demuestran una marcada tendencia a desempeñarse de manera sobresaliente en diversos escenarios (música, deportes, medicina, derecho, etc.) además de la academia, los cuales se convierten en referentes debido a que su influencia va más allá de su entorno, y entre los cuales podemos destacar representantes que van desde Michael Jackson, Edson Arantes -Pelé, Muhammad Ali, Usain Bolt, Benjamin Solomon Carson -Ben Carson-, Kwatsi Alibaruho, hasta Barack Obama.

Los logros individuales de las personas citadas, además de otras no incluidas, invitan a pensar que la capacidad va más allá de ese reduccionismo del color de piel, donde otros actores como Malcom X y Martin Luther King Jr. (reconocidos filósofos defensores de los derechos civiles de los afro-estadounidenses) y Nelson Mandela (activista contra el apartheid y primer mandatorio negro que encabezó el poder ejecutivo al resultar elegido por sufragio universal en Sudáfrica), nos permiten suponer que ello traspasa toda comprensión de lo absurdo de la segregación enmarcada solo en el color de piel olvidando derechos propios del ser humano, e incluso invita a pensar en que tanto el acceso pleno a educación de calidad como una vida en condiciones dignas para todos quizás es posible, y que solo depende de voluntades, al tiempo que obliga a preguntarse ¿hasta qué punto la superación de la barrera racial posibilitaría a las personas afrodescendientes desarrollar su verdadero potencial, y cómo ello podría favorecer a la sociedad?

Adicionalmente, no podemos olvidar la conexión del racismo con el ambiguo y controvertido concepto de raza, su complejidad, y su relación con los modelos de identidad, preceptos que para el caso de Latinoamérica, “... una vez la esclavitud fue abolida ..., tanto los(as) africanos(as) como los(as) afrolatinos(as) no se vieron así mismos en mejores condiciones y siguieron sufriendo las consecuencias de los discursos denigrantes creados en el marco del sistema esclavista.” (Reales, 2012, p.3), inclusive tal como lo afirma Wade (2011) "el problema del racismo se esconde en los márgenes de los nuevos discursos" (p.20), donde en las alocuciones asociadas se admiten expresiones de uso común en el argot popular haciendo que se vuelva costumbre su uso sin que evoquen conceptos racistas, lo cual ha hecho pensar durante muchos años que las cuestiones del racismo, equiparado al concepto de raza, "...instituida como una manera de legitimar las relaciones de subyugación y dominación..." (Romaña, 2020, p.24) eran propias de Estados Unidos, y que América Latina había sorteado los problemas raciales, lo cual está matizado por un discurso surgido del colonialismo que se apuntala en características fenotípicas singulares (color de piel, ciertas facciones, tipo de cabello, etc.) en la mayoría de personas que habitan estos territorios, englobando estos discursos en el concepto de identidad, sin poner de plano la marcada pero encubierta segregación existente, y que solo genera 
reacciones en los oprimidos, cuyo pensamiento no puede alejarse de las vejaciones a que fueron expuestos sus ancestros, e incluso ellos mismos.

\section{Los modelos de identidad y su relación con el racismo como pilares de una ciudadanía unívoca}

La problemática contenida en la segregación como una expresión o representación del racismo ${ }^{6}$ junto al significado de identidad son ambiguos porque, de un lado, se dan todo tipo de negaciones en tanto se alude a principios de desaprobación (clase dominante), mientras que del otro se incorporan expresiones de contradicción (clase dominada) toda vez que se tienen estereotipos en los cuales reflejarse (modelos relativos al físico, la belleza, el desempeño, la influencia social, etc.), pues "la homogenización del ideal estético que desmonta las peculiaridades de los distintos grupos humanos en toda su diversidad no permite construir una identidad racial legítima de autoaceptación -tal como se es- sin apuntar hacia el "blanqueamiento" ...." (Manzano, 2012, p.113), lo cual es común en Colombia y Brasil territorios en los cuales “... los cánones de belleza femenina están fuertemente estructurados por valores racializados que benefician la blancura (relativa): el cabello afro es «malo», lo que lleva a muchas mujeres negras a alisarlo; ..." (Wade, 2017, p.37), aunque sea expuesto en el marco de las interpretaciones; el racismo presupone la legitimidad de las clasificaciones raciales, ello es solo un fundamento para justificar la opresión, pues aunque se censura el racismo, los prejuicios causados no se abordan con la eficacia necesaria, solo se da un tratamiento ignominioso.

Algunos afrodescendientes cansados de situaciones de segregación e inequidad generadas por el racismo, sumado a ciertas experiencias de discriminación causadas a familiares o personas cercanas a su círculo social, exponen que se plantean al momento de considerar formar una familia elegir parejas de raza blanca con la finalidad de que sus descendientes, como un producto de la mezcla racial, adquieran características fenotípicas que les posibiliten un color de piel más claro, con lo cual puedan tener una mayor aceptación, intencionado además, a que no enfrenten las mismas dificultades de segregación que ellos, lo cual se acerca a un intento por "borrar marcas raciales históricas", lo que algunos autores denominan "blanqueamiento", generando así una inmersión social menos traumática, alejada tanto de la subordinación racial como de la desaprobación social típica de las sociedades con mayoría blanca, pues se considera que mientras más claro(a) se es de piel, mayores

\footnotetext{
${ }^{6}$ Grunstein (2005) la define como "un tipo específico de discriminación -pero no siempre por motivaciones racistas- que busca el distanciamiento físico para de esa forma mantener la separación social”. Cabe decir que "tampoco puede decirse que su ausencia implica la inexistencia de otras formas de discriminación y exclusión..." (p.96).
} 
son las posibilidades de ascenso social (Kolchin, 2002; Nayak, 2007; Roediger, 2006; Romaña, 2020; Wade, 2017); decisiones inclinadas hacia el imaginario de una posible mejora racial de futuros hijos, respecto de lo cual expone Wade (2003) que "... las mezclas supuestamente rompen con esquemas esencialistas de la identidad y, por tanto, abren la posibilidad de desestabilizar las relaciones jerárquicas del poder que sostienen y dependen de tales esquemas” (p.274) lo cual puede ser asimilado como un proceso de mestizaje del cual indica Wade (2003) que "(..) se entiende como un proceso mediante el cual se eliminan paulatinamente las poblaciones negras e indígenas, mientras se blanquea la población...” (p.277), supresión tendiente a alejar los señalamientos basados en el tono de piel (característicos de forma encubierta en Colombia) y los riesgos derivados de tales etiquetas, las cuales son estructuradas desde ideales y creencias enfocadas hacia los territorios.

A propósito de lo referente al mencionado "blanqueamiento" de manera reciente en Colombia se alzaron las voces de varios actores de raza negra (Nino Caicedo, Ray Charrupi, Belky Arizala) en contra de algunas producciones de los canales de Televisión RCN y Caracol; los actores negros representan a esclavos y trabajadores explotados, donde es normal escuchar expresiones como "negra estúpida", "bestia igualada" o "negro bastardo", situación que tiene molestos a algunos representantes de la comunidad afrodescendiente del país, quienes denuncian que "en la televisión colombiana blanquean a los personajes negros" ${ }^{7}$ toda vez que se reemplazan reconocidas artistas negras con personajes interpretados por actrices blancas, con lo cual se falsea la verdad de las historias y se relatan hechos no ocurridos, lo cual se debe al estereotipo que aún está marcado en la sociedad. Al respecto “...con el objetivo de eliminar los estereotipos racistas en la sociedad y en el sistema educativo, se da la implementación de la Cátedra de Estudios Afrocolombianos" (ONU, 2009, p.81) a la par de la instauración del día de la afrocolombianidad ${ }^{9}$, cuyos

\footnotetext{
${ }^{7}$ Exponen que se compró los derechos de Grey's Anatomy en cuya historia original hay personajes negros, y en la adaptación que hace la cadena de televisión colombiana no incluye actores de esta etnia; solo en la novela de médicos 'sala de urgencias' inspirada en ER se habló de un protagónico negro. Los actores a manera de protesta, exponen que se degrada y ofende a la raza negra, que se les denigra e irrespeta en televisión en tales producciones que solo hacen alusión a los esclavos.

Extraído de "En la televisión colombiana han blanqueado a los actores negros", disponible en https://www.kienyke.com/historias/en-la-television-colombiana-han-blanqueado-los-actores-negros

${ }^{8}$ La Cátedra de Estudios Afrocolombianos es una propuesta educativa que tiene como marco legal la Ley 70 de 1993, y el Decreto1122 de 1998, que en conjunto con los principios establecidos en la Constitución Política de Colombia, en torno a la interculturalidad, el reconocimiento y el respeto a la diversidad, busca la reivindicación de estas comunidades étnicas desde la apertura de espacios académicos pertinentes a la realidad cultural de las Comunidades Afrocolombianas, con la idea de resignificar y redignificar la cultura afrocolombiana, a partir de la contextualización histórica del proceso de esclavización al que fueron sometidos sus ancestros.
} 
propósitos están orientados a difundir la cultura afrocolombiana, fortalecer la identidad étnica de los afrodescendientes colombianos y rescatar su aporte a la historia nacional, la cual se incorpora como un intento por frenar o subsanar perjuicios causados en esta faceta de la segregación.

Los estereotipos racistas en la sociedad colombiana impiden que los afrodescendientes preserven sus rasgos identitarios y atributos característicos al ser expuestos a circunstancias de segregación, por lo cual tienden a perder su identidad (o reconocerla en situaciones puntuales) para ser tenidos en cuenta, es el caso por ejemplo de la televisión, donde por lo general los actores y actrices de raza negra ven relegada su participación aceptando simples papeles secundarios y actuaciones en tareas de servidumbre (debido a arraigos y condiciones de esclavitud), dada “... la falta de concordancia que existe en las sociedades latinoamericanas, entre el discurso y las prácticas sociales, de manera particular en torno al racismo ... duplicidad que es el resultado de la complejidad de los procesos identitarios en los pueblos ...." (París, 2002, p.293), quienes adoptan el cumplimiento de requisitos de belleza establecidos por la sociedad dominante (si no los cumple se reduce a actuar en comerciales de productos de aseo o como palenquera ${ }^{10}$ ).

Por otro lado, las personas negras son valoradas, generalmente en la televisión, por sus triunfos y logros inmediatos (en el marco de éxitos deportivos o musicales que enaltecen al país), lo que se traduce en un proceso de empatía interna e involuntaria donde el sujeto (que es parte de la sociedad dominante) se identifica con el otro (de la sociedad dominada) para compartir de manera momentánea ese sentimiento por el logro obtenido, a través de cierto estado de ánimo afable, lo cual se acerca al planteamiento de que "... la identidad se construye en interacción con otros, que es socialmente construida, que es un fenómeno eminentemente subjetivo e intersubjetivo, con un fuerte componente emocional y que su formación es un proceso de reconocimiento y valorización de la propia individualidad" (Manzano, 2012, p.109), aceptación poco presente en las sociedades dado que la pertenencia a un grupo racial puede definir el estatus, y a su vez, el estatus del individuo puede definir su posición en la escala racial, que sin duda alguna, se ha jerarquizado más allá de toda demostración, y que continúa siendo el escenario en el cual persiste la idea creada de que los afrodescendientes e indígenas poseen un superficial desarrollo intelectual,

\footnotetext{
${ }^{9}$ Con la Ley 725 del 21 de mayo del 2001 se conmemora el día de la afrocolombianidad, derivado de 4 eventos previos: la constitución del Estado de Cartagena prohibió el comercio y trata de negros en 1812; el dictador Juan del corral ordenó la libertad a los hijos de esclavos nacidos en Antioquia en 1812; se expide la Ley de libertad de vientre en 1821; el 21 de mayo de 1851 el Presidente de la República José Hilario López, firma la abolición de la esclavitud.

${ }^{10}$ Palenquera: mujeres de la región de Bolívar (Cartagena, Colombia) que vende frutas y dulces típicos; son descendientes de habitantes de San Basilio de Palenque, el primer pueblo libre de esclavos en América.
} 
concepto vertical que genera la ilusión de ser considerados solo para cierto tipo de labores, viendo restringido el acceso a otros niveles de desempeño.

La construcción social de la identidad a partir de la interacción y de la intersubjetividad, se ajusta a la relación que cada individuo guarda consigo mismo, con el entorno, con sus ancestros, y con el acceso a su propia historia pasada, donde se reconoce y valoriza la individualidad desde la intervención de un conjunto de valores y objetivos que estructuran su vida, designando aspectos tendientes al estatus y a la individualidad que pueden definir su posición en la escala racial, y pese a la diferenciación dentro de la especie, "la identidad racial la entendemos como parte de la identidad personal construida desde de la subjetividad ...; características que, desde la tradición han sido asignadas ... como valores, con el propósito de legitimar por parte del sujeto diferencias objetivamente existentes entre unos y otros" (Manzano, 2012, p.110); va más allá de la empatía con el otro, pone de manifiesto el hecho de que los individuos se encuentran en otra temporalidad, con relaciones sociales de identidad y poder jerarquizado variante conforme cambian las sociedades y sus modelos de identidad. En lo que a la segregación se refiere, el oprimida renuncia a su individualidad en favor de la comunidad bajo el supuesto de asegurar su libertad e igualdad como ciudadano político, pues se suscribe a un pacto social para ejercer sus derechos e intereses individuales siendo ciudadano, convenio en el que siempre podrá ser dominado bajo la tesis del bien común sobre el particular, porque

La idea de que los dominados son lo que son, no como víctimas de un conflicto de poder, sino porque son inferiores en su naturaleza material y espiritual, funcionaba y funciona como aniquilador de identidades plenas; al serles impuesta una identidad racial colonial y derogatoria, desprovista de su propio mundo histórico cultural, la fórmula consiste en enseñar a mirarse con los ojos del dominador. (Manzano, 2012, p.111),

imposición refrendada en la idea de que la finalidad del Estado es promover el bien común y preservar los derechos de los ciudadanos, lo cual desvirtúa la realidad, pues no hay ninguna acción que justifique el enunciado del racismo bajo cualquier representación o analogía, toda vez que resulta común la diferenciación amparada en los estereotipos, los prejuicios clasistas y los estigmas discriminatorios, los cuales son comunes en las relaciones de poder. Y esto se hace más evidente en la perpetuación de los sistemas y actitudes que confinan a la población indígena y afrodescendiente a ciertas áreas específicas de la estructura laboral, con los perfiles ocupacionales de peor remuneración, actividades domésticas o de aseo, ocupaciones de preferencia manuales, trato diferencial, total ausencia en la diplomacia y mínimo acceso a cargos directivos o de alto nivel, lo que se podría considerar una versión moderna de la esclavitud, que se complementa con la ubicación en los barrios marginales, escuelas 
con pocos recursos y de muy bajo nivel académico, viviendas en malas condiciones y con grave carencia de servicios públicos (agua potable, electricidad, alcantarillado), vías de comunicación en muy malas condiciones, etc., con lo cual se aprecia un tinte de segregación racial evidente, transmitida de generación en generación, obligando una marcada subalternización debido a que la discriminación aparece como una suerte de difusión institucional de la ideología racista provocando la desigualdad social (Hopenhayn y Bello, 2001; París, 2002; Reales, 2012), desigualdad convertida en parte integral de las estructuras sociales e ideológicas del Estado, cuyo diseño garantiza la dominación racial desde la clasificación de la población.

\section{La subalternización política representada en el racismo y los derechos negados}

En América Latina el flagelo del racismo apreciado en discriminación, segregación racial y desigualdad social, es un fenómeno que se extiende en la región, incluso en Guatemala (país con menos del 20\% de blancos quienes controlan el poder político y económico) o en Brasil donde según Reding (2007) "las oportunidades de la población afro-brasileña son muy limitadas a la hora de lograr una representación en el Congreso, educación, salud, empleo y en general todo lo necesario a la vida, porque el racismo sigue en pie" (p.163), y que se torna mucho más grave a partir de que "se estima que la población afro descendiente en América Latina supera los 150 millones de personas (30\% de la población), hecho que no muestra de ninguna manera su visibilidad ni política ni económica en los diferentes países de la región, ...." (García, 2008, p.21), posición que los margina obligándoles a depender de las decisiones de la clase dominante que ostenta el poder, y que en sumas se torna como un sofisma de distracción que se utiliza para justificar las relaciones entre las distintas clases sociales, ampliando la exclusión social, factor que alimenta la opresión, la dominación y la marginalización, ancladas en una subordinación estructural y culturalmente naturalizada.

La exclusión social expuesta en el racismo está explicada quizá por el planteamiento que hace Wade (2011) al decir que, “... los países de América Latina nunca evitaron el racismo, ni en el pasado ni hoy, ..." (p.18), acentuado mayormente en Brasil y Colombia, país último donde el censo del $2005^{11}$ reportó que la población afrocolombiana era de 4.311 .757 , cifra que representa un $10.4 \%$ del total nacional; sin embargo, más allá de la alta cifra de afrodescendientes, la desigualdad social se ejemplifica en que,

\footnotetext{
${ }^{11}$ Censo del 2005 realizado por el Departamento Administrativo Nacional de Estadística (DANE); incluye las categorías de raizal, palenquero, negro, mulato y afrocolombiano. Disponible en https://n9.cl/cre1
} 
... debido a la racialización del sistema de salud en Colombia, ... 106 de los 113 municipios donde la población negra constituye por los menos el 20\% no cuentan con unidades de cuidados intensivos ..., la inversión en salud en los municipios con numerosa población afrocolombiana es en promedio menor que el resto de municipios del país.” (Romaña, 2020, p.23)

Estos datos demuestran la persistencia de una racialización a nivel institucional, respecto de lo cual dice Wade (2011), "si el concepto de raza se sigue marginando en América Latina, aun en -Colombia y Brasil- ... para los afrodescendientes, es preciso reconocer que no está tan ausente como algunos piensan; y hay indicios de que gana terreno" (p.24), situación que está en manos del Estado, y se esconde en medio de variadas opiniones que tratan de hacer creer que la desigualdad social es más bien una problemática derivada de situaciones sociales anclada en factores económicos, negando que exista un problema de racismo.

La desigualdad presente en las estructuras sociales garantiza la dominación sistemática, y ello es así porque la clasificación racial crea relaciones verticales de dependencia en el imaginario, ampliando la brecha para que unos permanezcan en una posición inferior respecto a otros. "Por ello, debemos entender hoy en día el racismo como una ideología que mantiene ciertos mecanismos de categorización y de exclusión para ejercer el poder sobre sectores subalternos" (París, 2002, p.292), lo que describe un aspecto muy negativo de la organización social desde una distribución desigual de recursos, y frente a tal distinción, un caso ejemplarizante es el departamento del Chocó ubicado en el pacífico colombiano, donde cerca del 70\% de su población es afrodescendiente, y representa el mayor escenario de desigualdad racial evidente, con un territorio sumido en el abandono estatal a través de medios encubiertos del rol del racismo. Dicha población ha sido históricamente discriminada, pues en contraste, este es el territorio más rico en Colombia en cuanto a recursos naturales, aunque de manera paradójica es el más pobre en el contexto social, con sus dos principales vías de acceso al interior del país sin pavimentar, con exceso de fuentes hídricas pero ninguna red de acueducto que cubra a la población urbana por completo; hay mínima inversión en educación y salud por parte del Estado, lo cual demuestra que no se han logrado modificar los arraigados patrones de desigualdad racial sistemática, y que podría explicar el hecho planteado por Romaña (2020) cuando asegura que ".. aun cuando las personas afrodescendientes constituyen el 30\% de la población de las Américas, ellos y ellas se encuentran entre los grupos más pobres del continente" (p.24), donde la precaria situación de garantía de los derechos negados a este grupo étnico revela la existencia y persistencia del racismo estructural, sumado a muchos factores de exclusión y marginalidad, entre otras formas de vulneración. 
Podemos entender la historia de la subordinación como una lucha de resistencia contra la institución de las diferencias raciales, una disputa por equilibrar el influjo político marcado por la subyugación, que en Colombia, Brasil y EE. UU., de forma más visible, opera bajo un Estado racial que impide a las minorías vivir con dignidad, lo cual se visualizó mayormente a partir de 2 sucesos puntuales, el caso Floyd y el Covid-19. Por un lado, el asesinato del ciudadano afroamericano George Floyd a manos de la policía de Minneapolis (Minnesota), suscitó masivas protestas y manifestaciones por parte de ciudadanos en EE. UU., hecho que avivó el conflicto social y político inmerso en el racismo y la discriminación característicos en ese país.

Por otro lado, el distanciamiento social provocado por el Covid-19, producto de la crisis sanitaria, ha profundizado aún más la desigualdad racial exacerbando la racialización del contagio entre grupos excluidos como una consecuencia inexorable de la disparidad social, y que le imprime un tinte étnico-racial ya que una parte importante de las actividades de servicio que requieren de la presencia física del trabajador en labores de atención directa a la población, son desempeñadas por este particular grupo social, quedando expuestos a los riesgos de contagio.

Los dos sucesos citados reiteran las situaciones de segregación a la cual están expuestas las minorías a razón de encontrarse justo en medio de las líneas divisorias de la exclusión (política, laboral y en salud), apoyado por estructuras sociales y económicas de subordinación justificadas por una ideología de supremacía para la dominación de clases (Carbone, 2013; Rodríguez et al. 2020; Romaña, 2020), estructuras con un toque de cinismo oculto detrás de una fachada retórica que intenta justificar el alcance de las restricciones a que están expuestas las minorías, negándoles esos derechos individuales derivados de las normas sociales que permiten regular las relaciones interpersonales para vivir en comunidad, al margen de la tendencia del conflicto que está implícita en el segregacionismo.

Los derechos se tornan en simple teoría, su aplicación solo revela ambigüedades; por un lado, se expone que las personas están en igualdad de condiciones y merecen un trato con dignidad y respeto, de manera contraria, no se proporcionan herramientas para reivindicarlos, en tanto “... la precaria situación de garantía de los derechos de los pueblos indígenas y las comunidades negras revela la existencia y persistencia de racismo estructural en Colombia” (ONU, 2009, p.7), configuración que consiente los derechos individuales al tiempo que promueve distintas formas de igualdad, lo que decanta en situaciones que incluyen la negación de derechos, justificado en las acciones coercitivas de las instituciones que promueven los derechos comunes, lo cual se verifica a partir de que "el Estado colombiano ha reconocido que la situación social y económica de la población afrocolombiana es particularmente precaria. Sin embargo, por varios años negó que ello se debiera a una 
situación de discriminación” (Ibid., p.19), reconocimiento que certifica los derechos negados como parte integrante de actuaciones premeditadas, sin que haya un proceso de reivindicación a pesar del reconocimiento del pluralismo proclamado en la Constitución Política de Colombia de 1991 (C.P.C artículos 7 y 13) ${ }^{12}$ hacia las minorías, donde se observa que el Estado no les ha reconocido ciertos derechos, manteniendo incluso, la constante vulneración al derecho a la igualdad, en lo cual no es reconocida e identificada la consecuente desvalorización y discriminación latente (Isaza y Fajardo, 2008), vulneraciones que pasan desapercibidas en tanto que “... en Colombia no existe legislación para perseguir y sancionar los actos discriminatorios que se realicen con base en alguno de los criterios sospechosos establecidos en el artículo 13 de la Constitución Política" (ONU, 2009, p.28), agravado a partir de que el Estado no fomenta medidas correctivas (con consecuencias reales) que favorezcan a los grupos segregados y así promover que se garantice la igualdad. Ello exige cambios estructurales más allá de la negación de derechos, lo cual aumenta a la par en que la inequidad y la falta de oportunidades se entrelazan en la aplicación de manera hipócrita de las reglas del sistema.

\section{Conclusiones}

El tema del racismo y la segregación no siempre ha sido sensible con todos los grupos sociales afectados; es especialmente digno de atención debido a que sus acciones se transfieren en violencia personal, comunitaria, e institucional, con una alta carga psicológica.

El mestizaje es visto como un proceso de blanqueamiento pero que en ningún caso permite eliminar los prejuicios raciales, más bien da lugar a la jerarquización de variantes en la segregación y el racismo, el cual opera de un modo que dificulta reconocerlo como tal, pues se oculta en medio de la supuesta inclusión que propicia el mestizaje.

Con el final del sistema Jim Crow se sacuden los fundamentos ideológicos que sustentaban el racismo, dando apertura a una confluencia cultural de la diversidad africana, lo cual propicia la proliferación de multiplicidad de géneros culturales, poniendo en tela de juicio la ideología de la inferioridad racial en que se sustentaba el racismo, ya que representantes de la clase dominada demuestran una marcada tendencia a desempeñarse de manera sobresaliente en diversos escenarios.

\footnotetext{
12 Artículo 7. Marco constitucional colombiano para eliminar la discriminación racial, en lo que se refiere a la población afrocolombiana y a los pueblos indígenas; Artículo 13. reconoce explícitamente el derecho a la igualdad, al establecer que las personas son iguales ante la ley y que gozarán de los mismos derechos y oportunidades.
} 
La creencia ideológica del racismo fundamentada en la inferioridad racial en América Latina y Estados Unidos, no deja de ser un simple modelo que se perpetuó en lo absurdo de la opresión y la segregación, pues los logros individuales de algunos afrodescendientes invitan a pensar que la capacidad va más allá de ese reduccionismo del color de piel; solo fueron relegados del acceso pleno a oportunidades en condiciones de igualdad, privados de la oportunidad de tener una vida en condiciones dignas. "En el caso de Colombia, algunas de esas ideas racistas han sido promovidas por políticos de la élite nacional. ..." (Romaña, 2020, p.21), lo cual se complementa con “... existentes narrativas públicas racistas lideradas por referentes de la patria ..., que laceran a nivel psicológico y moral a las personas, grupos o pueblos aludidos, denigrando su identidad" (Mosquera y León, 2010, p.51), declaraciones y juicios que dan mayor sustento al anclaje de comportamientos de exclusión en contra de las minorías.

En Colombia las comunidades negras expuestas al racismo histórico y actual aprecian el reconocimiento de derechos colectivos en función de su estatus como grupo étnico portador de una identidad propia y no del color de la piel de sus integrantes, criterio que tal vez se emplea para no caer en posibles contradicciones por parte el Estado.

El racismo presupone la legitimidad de las clasificaciones raciales como fundamento para justificar la opresión; se esconde en los márgenes de los nuevos discursos donde se aceptan expresiones de uso común en el argot popular haciendo que se vuelva costumbre su uso sin que evoquen conceptos racistas, lo cual ha hecho pensar durante muchos años que las cuestiones del racismo, equiparado al concepto de raza eran propias de EE. UU., y que América Latina había sorteado los problemas raciales.

En la problemática contenida en la segregación como una representación del racismo se tienen estereotipos en los cuales reflejarse, los cuales han ido modificando las costumbres y creencias de las minorías segregadas, en particular de los afrodescendientes, alterando su idiosincrasia, obligándolos a huir de su historia, a esconder esa realidad racial que a diario los persigue, lo cual es común en Colombia y Brasil en donde los cánones de belleza femenina están fuertemente estructurados por valores racializados que benefician la blancura relativa.

Algunos afrodescendientes cansados de situaciones de segregación e inequidad generadas por el racismo y la discriminación, se plantean formar una familia eligiendo parejas de raza blanca con la finalidad de que sus descendientes adquieran características fenotípicas que les posibiliten un color de piel más claro "blanqueamiento", con lo cual puedan tener una mayor aceptación, y así alejarse de la segregación y la subordinación racial. 
Pese a que algunos afrodescendientes han alcanzado grandes logros, y demostrado que no es el color de la piel el condicionante para determinar las capacidades, suena absurdo que aún la sociedad enfrente el tema del racismo y la discriminación; las minorías deben dar el 100\% para tener las mismas posibilidades que aquellos de cierta condición étnica favorecida, debido a que solo son exaltados por los logros deportivos individuales que enaltecen al país, tornándose una práctica disimulada e hipócrita, en medio de prácticas de segregación muy sutiles.

Contrario a toda realidad, la identidad de los afrodescendientes en Colombia se preserva al margen de su propio sentir, tienden a perder su identidad para poder ser aceptados, más allá de todo desprecio en torno al estatus social que les es asignado; renuncian a su individualidad bajo el supuesto de asegurar su libertad e igualdad como ciudadanos políticos.

El proceso de mestizaje elimina paulatinamente las poblaciones negras e indígenas, mientras se blanquea la población, supresión tendiente a alejar los señalamientos basados en el tono de piel y los riesgos derivados de etiquetas estructuradas desde ideales y creencias enfocadas hacia lo racial.

La desigualdad presente en la escala jerárquica propicia la subalternización hacia minorías como indígenas y afrodescendientes, lo cual los margina, ampliando su exclusión social, aumentando la opresión la cual está anclada en una subordinación estructural y culturalmente naturalizada, "el racismo en Colombia, ... dificultó el acceso a oportunidades de estudio y/o laborales a dichas poblaciones, y obstaculizó la apertura de espacios de participación política; marginalizándolas y teniendo esto implicaciones, incluso, en su calidad de vida" (Camargo, 2011, p.55). En este país, esto se traduce en apellidos históricamente asociados con el conglomerado empresarial y su participación en los partidos políticos, que son mecanismos a través de los cuales se han perpetuado en el poder.

Se revela la aplicación ambigua de los derechos individuales a la par de la promoción de distintas formas de igualdad, lo que decanta en situaciones que incluyen la negación de derechos, las acciones coercitivas de las instituciones que los promueven y sin que haya un proceso de reivindicación.

En América Latina el flagelo del racismo apreciado en discriminación, segregación racial y desigualdad social es un fenómeno que se extiende en la región, caracterizado por limitadas oportunidades de la población afrodescendiente, más allá de que superan el 30\% de la población total, hecho que no muestra de ninguna manera su visibilidad ni política ni económica en los diferentes países de la región.

La desigualdad presente en las estructuras sociales garantiza la dominación sistemática creando patrones de desigualdad racial sistemática, donde la precaria situación de garantía de los derechos negados a los afrodescendientes revela la 
existencia y persistencia del racismo estructural, sumado a factores de exclusión y marginalidad, entre otras formas de vulneración.

Los derechos fundamentales de las minorías, su protección y valoración están en el imaginario, pues el Estado no está en condiciones, ni tiene la voluntad para que se haga efectivo su reconocimiento legal, más allá de haber legitimado la diversidad étnica del pueblo afrocolombiano. La lucha para defenderlos debe darse de forma más abierta, debe traspasar las fronteras geopolíticas, abrirse a la justicia y la verdad.

\section{Referencias bibliográficas}

Camargo, M. (2011). Las comunidades afro frente al racismo en Colombia. Encuentros. (2), pp. 51-60. ISSN 1692-5858. Recuperado de https://dialnet.unirioja.es/descarga/articulo/4050031.pdf

Carbone, V. L. (2013). Raza y Racismo: ¿el motor de la historia de los Estados Unidos? Un acercamiento a la relación entre raza, racismo y clase en la historia norteamericana. XIV Jornadas Interescuelas / Departamento de Historia de la Facultad de Filosofia y Letras. Universidad Nacional de Cuyo, Mendoza. Recuperado de https://forum.lasaweb.org/files/vol46-issue1/Debates-2.pdf

Constitución Política de Colombia [C.P.C]. (1991). Consejo Superior de la Judicatura. Gobierno de Colombia. Recuperado de https://www.corteconstitucional.gov.co/inicio/Constitucion\%20politica\%20d e\%20Colombia.pdf

García, F. (2008). Identidades, etnicidad y racismo en América Latina. ISBN: 978-997867-187-0. Ed. FLACSO Ecuador y Ministerio de Cultura del Ecuador. Recuperado de https://biblio.flacsoandes.edu.ec/libros/digital/41402.pdf

Grunstein, A. (2005). Segregación y discriminación: el nacimiento de Jim Crow en el sur de los Estados Unidos. El Cotidiano, (134), pp. 95-102. ISSN: 0186-1840. Disponible en https://www.redalyc.org/pdf/325/32513413.pdf

Hopenhayn, M. y Bello, A. (2001). Discriminación étnico-racial y xenofobia en América Latina y el Caribe. CEPAL - SERIE Políticas sociales 47. ISBN: 92 1321849-4. Recuperado de https://repositorio.cepal.org/bitstream/handle/11362/5987/1/S01050412_es. pdf

Isaza, P. y Fajardo, P. J. (2008). Igualdad, discriminación racial y comunidades negras en la jurisprudencia constitucional colombiana. Monografía para optar al título de Abogado. Universidad EAFIT. Departamento de Derecho. Medellín. Recuperado de https://repository.eafit.edu.co/bitstream/handle/10784/460/PedroJose_Fajar doUribe_2008.pdf? sequence $=1 \&$ isAllowed $=y$ 
Kolchin, P. (2002). Whiteness studies: the new history of race in America. Journal of American History, 89(1), pp.154-173. Disponible en https://academic.oup.com/jah/articleabstract/89/1/154/688936?redirectedFrom

Maestro, J. (2009). El dilema norteamericano. De la esclavitud a la institucionalización de la discriminación racial. Stud. hist., H.a cont., (26), pp. 5378. Recuperado de https://www.researchgate.net/publication/277267033_El_dilema_norteameri cano_De_la_Esclavitud_a_la_institucionalizacion_de_la_discriminacion_racial /link/558903a408aeb2994444c173/download

Manzano, M. (2012). Identidad racial: Un problema social en nuestros días. Límite. Revista de Filosofia y Psicología. Vol. 7, (26), pp. 107-119. ISSN: 0718-1361. Recuperado de https://www.redalyc.org/pdf/836/83625847007.pdf

Mosquera, C. y León, R. (2010). Acciones afirmativas y ciudadanía diferenciada étnicoracial negra, afrocolombiana, palenquera y raizal. Entre bicentenarios de las Independencias y Constitución de 1991. Bogotá: Universidad Nacional de Colombia. https://www.flacsoandes.edu.ec/sites/default/files/\%25f/agora/files/los_bice ntenarios_de_las_independencias.pdf

Nayak, A. (2007). Critical whiteness studies. Sociology Compass, 1 (2), 737-755. Disponible https://www.researchgate.net/publication/229488024_Critical_Whiteness_St udies

ONU. (2009). Discriminación racial en Colombia: informe alterno ante el Comité para la Eliminación de la Discriminación Racial de la ONU 2009 - CEDR. Programa de Justicia global y Derechos Humanos. Documentos Número 1. ISSN 2145-2369. Recuperado de https://www.dejusticia.org/wpcontent/uploads/2017/04/fi_name_recurso_206.pdf

París, M. D. (2002). Estudios sobre el racismo en América Latina. Politica y Cultura, (17), pp. 289-310. ISSN: 0188-7742. Recuperado de https://www.redalyc.org/pdf/267/26701714.pdf

Pérez-Concepción, H. R. (2010). La situación del negro en Estados Unidos en la época de la protesta armada de los independientes de color en Cuba. Ciencia en su PC, (4), pp. $116 \quad-131 . \quad$ ISSN: 1027-2887. Recuperado de https://www.redalyc.org/pdf/1813/181317854009.pdf

Reales, L. (2012). Pobreza y discriminación racial en América Latina: El caso de los(as) afrodescendientes. Avance de tesis de Postdoctorado. Recuperado de https://www.corteidh.or.cr/tablas/r23378.pdf 
Reding, S. (2007). Diversidad y racismo en América Latina. Latinoamérica. Revista de estudios Latinoaméricanos. (44), pp. 157-179. Recuperado de http://www.scielo.org.mx/pdf/latinoam/n44/2448-6914-latinoam-44157.pdf

Rodríguez, et al. (2020). Estados Unidos: miradas críticas desde nuestra América. CLACSO. Boletines de grupos de trabajo (4). ISBN 978-987-722-635-5. Recuperado de https://www.clacso.org/wpcontent/uploads/2020/07/V3_Estados_Unidos_Miradas_criticas_N4.pdf

Roediger, D. R. (2006). Working toward whiteness: how America's immigrants became white. New York: Basic Books. Disponible en https://www.amazon.com/Working-Toward-Whiteness-AmericasImmigrants-dp-1541673476/dp/1541673476/ref=dp_ob_title_bk

Romaña, Y. A. (2020). El racismo en la cotidianidad: una manifestación del racismo estructural en Colombia. UNA Revista Derecho(En linea). (5), pp. 12-62. e-ISSN 2539-5343.

Recuperado

de https://una.uniandes.edu.co/images/Volumen5/20202---1.RomaaRivas.pdf

Wade, Peter. (2003). Repensando el mestizaje. Revista Colombiana de Antropología. Volumen 39, pp. 273-296. Disponible en http://www.scielo.org.co/pdf/rcan/v39/v39a09.pdf

Wade, Peter. (2010). Race and Ethnicity in Latin America. Second Edition. London: Pluto Press. ISBN 978-07453-2948-2. Disponible en https://library.oapen.org/bitstream/handle/20.500.12657/45656/625258.pdf? sequence $=1 \&$ isAllowed $=\mathrm{y}$

Wade, Peter. (2011). Multiculturalismo y racismo. Revista Colombiana de Antropología. Volumen $47 \quad(2), \quad$ pp. 15-35. Disponible en https://www.redalyc.org/pdf/1050/105021311002.pdf

Wade, Peter. (2017). Estudios afrodescendientes en Latinoamérica: racismo y mestizaje. Tabula Rasa. (27), pp. 23-44. ISSN 1794-2489. Disponible en http://www.scielo.org.co/pdf/tara/n27/1794-2489-tara-27-00023.pdf

Wade, Peter. (2021). Racismos latinoamericanos desde una perspectiva global. Revista Nueva Sociedad. NUSO, N. 292/marzo-abril 2021. Etnicidades y racismo en América Latina. pp. 25-41. Disponible en https://static.nuso.org/media/articles/downloads/1.TC_Wade_292.pdf 